\title{
HISTOIRE CROISÉE ALS ONDERBOUW BIJ ONDERZOEK NAAR PRIMITIEVE REBELLEN - CASUS JAN DE LICHTE VAN LOUIS PAUL BOON (VLAANDEREN) EN JURAJ JÁNOŠÍK VAN ANDREJ MELICHERČÍK (SLOWAKIJE)
}

\author{
BENJAMIN BOSSAERT
}

\begin{abstract}
Histoire croisée - entangled history as the foundation for research about primitive rebels: the case of Jan de Lichte van Louis Paul Boon (Flanders) and Juraj Jánošík by Andrej Melicherčík (Slovakia)

In this contribution we focus on the study of so-called social bandits, as they are known from the study Primitive Rebels by Eric Hobsbawm (1959). We focus more specifically on the Flemish case of Jan de Lichte and the Slovak case of Juraj Jánošík. In this contribution we use the histoire croisée method, suggested by the French-German historians Werner and Zimmermann (2006). They claim that in this "crossed history", social, cultural and political groups are under intercultural influence and offer an alternative to the dominant national point of view. We perceive the hero-image around both heroic figures from the 1950s and 1960s in a distinct Marxist tradition and notice a different image in the Flemish literary adaptation, which remained to a large extent a regional phenomenon.
\end{abstract}

Key words: Primitive rebels; rural outlaws; entangled history; hero; image

\section{Omkadering van het onderwerp: de casus Jan de Lichte versus Juraj Jánošík. Heldenvorming in het pantheon van de nationale beweging.}

De lange negentiende eeuw (1800-1914) wordt ook wel de eeuw van het nationalisme genoemd. In het postnapoleontische Europese staatsbestel vonden er bijzondere processen van nation building plaats, in de eerste plaats door academici en schrijvers, later door journalisten, politici en activisten. Deze leidden tot een massaal natiebesef en de premisse, dat de taal een basiscategorie is om een natie te vormen, conform het romantische ideaal van de Duitse filosoof Herder. Het was de Tsjechische historicus-socioloog Miroslav Hroch, die reeds in 1968 een omvangrijk werk schreef dat kleinere Europese nationale bewegingen in de lange negentiende eeuw met elkaar vergeleek. Hij zette ze in een drieledig fasenmodel van A. wetenschappelijke interesse, B. politieke agitatie en C. de massale volksbeweging. 
Zijn werken Die Vorkämpfer der nationalen Bewegung (1968) en Obrození malých evropských národi̊ (1971), werd pas door zijn Engelse gezamenlijke bewerking Social preconditions of national revival in Europe in 1985 door historici die nationalisme-onderzoek in bredere context bekeken, wijder verspreid en opgepikt in de West-Europese geschiedschrijving via onder meer Ernest Gellner in zijn Nations and nationalism (1983).

Historicus Luc Boeva (2009) merkt op dat er vijf subjectieve factoren nodig zijn om van een nationale beweging een massa-beweging te maken en ze zo naar fase $C$ van het model van Hroch te leiden: de natiebouwers als sociale agitatoren, een belangenconflict, een historische constructie, taalstrijd en ten slotte de culturele constructie. Wij zouden vooral de laatste twee factoren willen benadrukken als significant voor de Slowaakse en de Vlaamse beweging en deze als uitgangspunten nemen voor een vergelijking. Het is onder meer door wetenschappers als Joep Leerssen (1999), die nationalisme als cultureel fenomeen met een wisselwerking tussen cultuur en nationaal denken onderstreept hebben, dat we in de geschiedenis een inbreng krijgen van literatuurwetenschap, imagologie en culturele constructies. Men bouwt aan, om het met de oriëntalist Benedict Anderson te zeggen, een zogenaamde verbeelde gemeenschap.

Bij culturele constructies horen naast een zo vroeg mogelijk traceerbare geschiedenis of een schijn van historiciteit ook helden, die in een soort pantheon van de natie kunnen bijgezet worden en kunnen dienen als voorbeelden voor de kleine landen. In deze bijdrage zetten we graag een specifiek type held uiteen, namelijk dat van de rural outlaw of in een vroeger stadium genaamde primitieve rebel. We spitsen ons toe op het type held van de zogenaamde primitive rebels, zoals ze vermeld en getypologiseerd worden in het vroege onderzoek van Eric Hobsbawm (1959). Enkele belangrijke onderzoeksvragen gaan we rechtstreeks toepassen op de casus van Juraj Jánošík ${ }^{1}$ en Jan de Lichte. Recenter publiceerden de Duitse literatuurtheoretica Ute Rasslof specifiek over Jánošík (2010, ook gepubliceerd in Neubauer \& Leerssen 2010) en ook John Neubauer en Joep Leerssen (2010) over typologieën van rural outlaws en slechteriken, villains.

We kunnen ons de vraag stellen of geschiedenis überhaupt bekeken kan worden als een zaak van individuelen die voor een zaak strijden groter dan hun eigen belangen. In een poging tot definitie van een nationale held zouden we kunnen stellen dat hij of zij een zekere toewijding moet hebben tegenover een natie. Er is een bepaalde charismatische autoriteit nodig, die bovendien door een groep mensen moet worden aanvaard. Historische helden hebben een leven gehad, waard om het na te volgen of ook te beleven. Maar sommige helden kenden een mythologiseringsproces dat wijzigde in de loop der tijden, en enkele helden werden niet geaccepteerd in hun nationale beweging. Men zou kunnen spreken van een detrimental hero of schadelijke, ongunstige held. Het is een veranderlijk, meanderend concept. Dit concept kunnen we toetsen op zijn werkbaarheid en is ook het uitgangspunt van ons promotieonderzoek (Bossaert 2016: 179-183).

Het idee van een veranderende heldenfiguur in de historische nationale beweging lijkt ons interessant als leidraad bij de twee figuren in onze casus, die in principe historisch als misdadigers geboekt staan. De hoofdvraag die we ons kunnen stellen is: welke factoren kunnen er van belang zijn dat een held als Jánošík succesvol in een soort van Slowaaks

1 In Hobsbawm (1959: 13) beschrijft Eric Hobsbawm de Slowaaks-Poolse Jánošík samen met Robin Hood en de Spaans-Andalusische roverhoofdman Diego Correntes als een van de archetypische voorbeelden van de sociale bandiet of primitieve rebel. 
pantheon van helden is geraakt, terwijl de figuur van Jan de Lichte, die nochtans in vele grote lijnen historisch, mythologisch, narratologisch en zelfs visueel overeenkomt met de Slowaakse primitieve rebel, in grote mate een regionaal fenomeen bleef . Weliswaar blijven ook in de casus van Jan de Lichte diverse voorbeelden van beeldvorming bestaan in de vorm van adaptaties (toneelstukken, luisterspelen, strips), lieux-de-mémoire en herdenkingen, of andere adaptatievormen. We bekijken en vergelijken deze twee helden vanuit hetzelfde referentiekader, volgens het fenomeen schriftelijke folklore in de definitie van Aleida Assmann (1983) en brengen ze samen met behulp van histoire croisée.

\section{Schriftelijke folklore en histoire croisée: de onderbouw}

De term "schriftelijke folklore" werd in 1983 gelanceerd door Aleida Assmann en berust op een synthese van het door Jakobson gemaakte onderscheid tussen "folklore" als kenmerkende vorm van tekstoverdracht in mondelinge culturen en "literatuur" als kenmerkende vorm van tekstoverdracht in schriftculturen. Schriftelijke folklore is geschreven tekst die op folkloristische wijze wordt overgeleverd. Het gaat hier dikwijls om verhaalstof die cultuurgrenzen overschrijdt, zonder dat men weet waar of wie de auteur van de oerstof is. Schriftelijke folklore bestaat uit compilaties van teksten, of delen van teksten, aangepast aan de tijd en het publiek, waardoor ze het karakter van gebruiksteksten krijgen, functioneel slechts voor een bepaald publiek in een bepaalde periode. (Assmann geciteerd in Parlevliet 2009: 36-37).

Naast het cultureel onderzoek van Assmann willen we ons ook concentreren op de theoretische paradigma's van de culturele transfer en mogelijke uitdagingen en problemen die het onderzoek naar cultuur en nationaal denken met zich meebrengen. De kanttekeningen die de Franse historici Werner en Espagne plaatsten bij comparatief onderzoek (overzichtelijk uitgewerkt door Marjet Brolsma, zie www1) - en die zij en andere wegbereiders van de cultuurtransfer in latere artikels verder uitwerkten - komen hoofdzakelijk op de volgende punten neer. Allereerst veronderstelt de vergelijkende methode van culturele transfer dat cultuurgebieden samenvallen met de grenzen van de natiestaat. Onderzoekers nemende natie vaak per definitie als uitgangspunt van een vergelijking. Het benoemen van verschillen en overeenkomsten tussen twee landen brengt echter het gevaar met zich mee dat deze gekleurd worden door de nationale cultuur en achtergrond van de onderzoeker. Werner en Espagne pleiten voor het doorbreken van nationale kaders en beschouwen cultuurgebieden (aires culturelles of Kulturräume) als dynamische eenheden in plaats van als afgesloten entiteiten. De cultuurtransfer onderscheidt tal van verschillende cultuurgebieden, zoals een bepaalde regio, een groep emigranten of een internationaal netwerk. (www1). Vervolgens stelt men in ander onderzoek een alternatieve kijk voor. Een bijzonder voorbeeld daarvan vormt de zogenaamde histoire croisée.

Werner en Zimmermann (2003) pleiten ervoor om het onderzoek te richten op histoire croisée, op de vervlechtingen en kruisingen in de geschiedenis en daarbij dus de (nationale) referentiekaders en ook de transfer als primair onderzoeksobject los te laten. Dit heeft als voordeel dat ook kruisingen waarbij er geen sprake is van een directe, concrete en expliciete transfer bestudeerd kunnen worden. De histoire croisée is volgens Werner 
en Zimmermann dynamisch, wederkerig en transformatief en doet recht aan het feit dat veranderingen ook op een later tijdstip of indirect kunnen plaatsvinden. Een tekortkoming van de histoire croisée is dat het concept, evenals de cultuurtransfer, wel theoretisch uitgewerkt en geproblematiseerd is, maar weinig handreikingen biedt voor een praktische aanpak. Het enige wat Werner en Zimmermann hierover meedelen is dat de gekruiste geschiedenis zich het beste laat opsporen en analyseren door een methode van pragmatische inductie, waarbij het onderzoeksobject zelf als uitgangspunt moet worden genomen in plaats van de context of de theorie (Brolsma, www1). We nemen nu de rural outlaw als onderzoeksobject en bekijken even de geschiedenis van de schriftelijke folklore bij beide typehelden in de respectieve Vlaamse en Slowaakse nationale beweging.

\section{De schriftelijke folklore bij Jan de Lichte en Juraj Jánošík in historisch perspectief.}

Het meest precieze overzicht van de "folkorisering" van de historische held Jan de Lichte naar een traditie van volksverhalen, werd onderzocht door Paul Maes samen met professor volkskunde Stefaan Top (1982). Zij geven een overzicht van de roverij in Vlaanderen waarbij ze meedelen dat de figuur van Jan de Lichte, naast de bende van Bakelandt en de Limburgse Bokkenrijders, wellicht vandaag de dag de meest bekende roversfiguur is. Het was pas in de tweede helft van de negentiende eeuw dat de legende van Jan de Lichte voor een breder publiek bekend werd. In 1873 schreef de amateur-historicus Ernest Ternest uit Wetteren een semi-historische roman over onze bendeleider, deels gebaseerd op feiten, maar hij gebruikte ook een substantieel deel uit volksvertellingen en de mondelinge overlevering in zijn roman, die mensen elkaar vertelden over de verschrikkelijke daden van Jan de Lichte rondom Aalst. Een tweede roman, De groote bende van Jan de Lichte, Bewerkt naar de oorspronkelijke processtukken, en de meest herhaalde en meest verspreide overleveringen, verscheen in 1888 van de hand van een anonieme auteur. De populaire roman van Hans van Hoorenbeek (pseudoniem van Abraham Hans) uit 1908, Jan de Lichte en zijn zwarte rooversbende, was volledig fictie. Deze roman was gebaseerd op vroegere versies van de volksverhalen en heeft een plot die vooral focust op een liefdesverhaal tussen het roven door. Er wordt een intrige geïntroduceerd tussen een archetypische schurk, de Franstalige kasteelheer Johan De Creil, die zijn dochter te gelde wil maken; zij kan enkel door de bende gered worden door het bestelen van de diligence. Deze roman heeft stellig Louis Paul Boon geïnspireerd tot zijn versie van Jan de Lichte, hoewel hij zelf ook zijn grootvader Peetje Sooi vermeldt, die een boek had waaruit de verhalen kwamen. (Van 't Hof 1979: 325) De volksvertellingen en de populaire romans beeldden onze held vaak uit als een rebel die geld van de rijken stal en het aan de armen gaf, genade vond bij vele armen en zelfs een soort van verzet leidde tegenover de heersende klasse, waarvan we heden ten dage weten dat dit een anachronisme was, omdat we goed weten, dat er eigenlijk geen land was dat echte controle uitoefende over het door oorlog zwaar getroffen Land van Aalst. Er zijn ook (onware, niet-historische) religieuze motieven in verweven; sommige volksvertellingen vertelden dat Jan de Lichte zijn echte geloof opbiechtte tot een priester toen hij ter dood werd veroordeeld (Humbeeck 2007: 392-394). 
Maes en Top concluderen (1982: 26-27) dat het werk van Ternest wellicht het meest bijdroeg tot het legendariseren van de volksverhalen in een coherente en bovendien populaire volksroman, die tot 1926 nog herdrukken kende. Ook Louis Paul Boon liet zich deels door Ternest inspireren. Het is pas Boon die van de bendeleider een "tedere anarchist" maakte en geheel in zijn stijl een eigen visie aan de held toevoegde. Maes en Top beweren dat Boon wel de anonieme roman van de roversbende kende maar door zijn originele verwerking en zijn menselijke visie op de historische feiten er een origineel werk van gemaakt heeft. Dat anarchisme, nihilisme, de aantrekkelijkheid van het communisme en het zoeken naar alternatieve ideologieën vinden we wel meer terug in de literaire tradities na de Tweede Wereldoorlog.

Laten we in contrastief verband de folklorisering van de Slowaakse casusheld Jánošík onder de loep nemen. Vooral onder impuls van de Poolse onderzoeker Joanna Goszczyńska (2003) legde men verscheidene mythen bloot over Juraj Jánošík die men vond in de folklore en de mondelinge overlevering en zij vond ook een mogelijke reden voor de populariteit van Jánošík in het Slowaakse nationale bewustzijn. Het was haar verdienste dat zij vooral de grote discrepantie tussen zijn straf en zijn misdaden (Jánošík eindigde aan de galg en werd met een touw om zijn middel opgehangen, stierf eerder aan ontbering dan door het marteltuig) als een van de doorslaggevende motieven voor zijn grote heldendom naar voor schoof. Al van het prille begin was de uitbeelding van deze held niet enkel positief of negatief. Sommige schrijvers en denkers schilderen hem af als een man die vocht en de armen beschermde tegen de Hongaarse bovenklasse, anderen veroordeelden zijn uiterlijk als een outlaw en laakten zijn gevoel voor wanorde. Zijn heldenstatus werd pasnuttig, in positieve zin omgebogen en gebruikt door Ludovít Štúr, politicus, leraar en codificator van het standaardslowaaks.

Štúr besliste om Jánošík onder te brengen in een pantheon van Slowaakse nationale helden en lanceerde een specifieke poëtica die de jonge Slowaakse auteurs zouden moeten gebruiken om een nieuwe literaire traditie te creëren in het Slowaaks. Aangezien er pas een nieuwe schrijftaal was, had men ook helden en een literaire traditie nodig. Vóór de codificatie van het Slowaaks konden we echter al afbeeldingen van Janošíkfiguren vinden in het oeuvre van Bohuslav Táblic (1809), die jaarmarktliederen als bron gebruikte en ook in de Slavische Geschichte van Pavol Jozef Šafárik, een vurig supporter van de zogenaamde Slavische vzájemnost, een intensieve wederzijdse samenwerking tussen de Slavische landen en culturen in de vorm vanhet uitwisselen van Slavische interculturele contacten. Beiden mengden folklore-elementen met karaktertrekken als moed, kracht en zelfs magische krachten. Šafárik gaat nog verder en schildert Jánošík zelfs als een ware Christusfiguur af, die verraden werd, geleden heeft en gefolterd werd voor zijn eigen, Slavische volk. Ján Kollár, een Slowaakse evangelische predikant die hevig de Tsjecho-Slowaakse werderzijdse relaties verdedigde, had aan de andere kant geen goed woord veil voor Jánošík: hij plaatste onze rebel in zijn meesterwerk Slávy dcéra (de dochter van Sláva) in een allegorische hel, omdat volgens Kollár roven niets dan slecht was en een doodzonde (Goszcyńska 2007: 60).

Goszcyńska (2007: 76-77) poneert dat drie auteurs cruciaal waren om Jánošík te transformeren naar een geliefde, populaire en nationale held: Stefan Marko Daxner, Samo Chalupka en Janko Král.' Král stond bekend als een revolutionaire poëet en werd later ook door Slowaakse literaire historici als dusdanig gecanoniseerd, dus het hoeft 
niet te verbazen dat hij zelf een voorbeeld nam aan de heroïsche, romantische dood van Juraj Jánošík. Het idee dat een bandiet, een rover zijn vrijheid kende, waar het roven een symbool wordt van een strijd voor een Slowaakse natie, dat werd het belangrijkste aspect van Juraj Jánošík. Janko Král'bestudeerde ook de originele processtukken van onze rebel en hij wilde een belangrijker werk schrijven dan enkel gedichten over hem, maar overleed jammer genoeg op jonge leeftijd.

Andere auteurs van deze jonge beloftevolle generatie (waaronder de al genoemden Daxner en Chalupka) volgden wel de romantische poëtica van de beweging van Ludovít Štúr, die zei dat het eerste doel van de Slowaakse nationale beweging was om een literaire traditie te creëren. Opvoedkundige motieven stonden voorop. Hij moest niets weten van het idee van een Byronic Hero in een roman, want dit was een te individualistische held, die kon zich nergens voor ten dienste stellen. $\mathrm{Na}$ de revolutie en de lente der volkeren van 1848 begon dit literaire concept echter te wijzigen, want vele Slowaakse intelligentsia waren ontevreden met de resultaten van deze (mislukte) revolutie, waar de Slowaakse pogingen tot natievorming onderdrukt werden door de keizerlijke troepen met wie ze samen tegen de Hongaarse opstandelingen hadden gestreden. De schrijver Ján Botto schrijft met zijn Smrt'Jánošíkova (de dood van Jánošík) een werk dat tot op vandaag een klassieker blijft in de Slowaakse literatuur. Hij inspireerde zich op folklore-elementen, maar zorgde voor een split in de poëticale opvattingen van de generatie van Štúr-aanhangers en creëerde een zogenaamde messianistische held, die vecht en strijdt voor zijn vrijheid tegenover vreemde onderdrukking. Het idee van een mythische held bleef aantrekkelijk in de jaren zestig van de negentiende eeuw (bijvoorbeeld in het minder bekende werk Matora van Michal Miloslav Hodža) en vormde het basismotief voor latere romantische en populaire literatuur. Deze literatuur ging steeds verder af staan van het basismotief van de rural outlaw. (Goszcyńska 2007: 112-115)

\section{De jaren vijftig en zestig van de twintigste eeuw: sociale geschiedschrijving}

De Bende van Jan de Lichte bekleedt een interessante positie in het oeuvre van Louis Paul Boon. Van 't Hof (1979: 325) vermeldt dat "De bende van Jan de Lichte een van de eerste boeken [is] waarin hij een geschiedkundig onderwerp behandelt. Later is hij steeds meer 'geschiedenis' gaan verwerken". Zijn visie is dat de opstand van de bendeleider een echte prelude vormde op de Franse revolutie. We merken uit de editiegeschiedenis dat het verhaal van Jan de Lichte, dat in feuilletonvorm in het Laatste nieuws verscheen, in boekvorm gepubliceerd wordt in 1953, maar dat de laatste versie uit 1957 veel minder de nadruk legt op het revolutionaire karakter van de bende ('t Hof 1979: 327). Boon vertelt het verhaal van Jans bende - net als andere volksboekschrijvers - heel realistisch, spannend en smeuïg. Hij schrijft wel degelijk een volksboek maar daarnaast relativeert hij het verhaal én het genre door in de commentaren die hij als verteller geeft en later in diverse interviews heel duidelijk zijn persoonlijke kijk op het verhaal en 'de revolutie' te geven. Zo ondersteunt de afwijkende vorm van Boons volksboek de revolutionaire inhoud ervan. ('t Hof 1979: 338). Weisgerber (1962: 229) wijst er op dat Boon eigenlijk als eerste schrijver in de schriftelijke folklore van Jan de Lichte hem tot een echte held verheft: 
"In De Bende van Jan de Lichte gaat zijn sympathie uit naar de struikrovers, van wie hij helden maakt die met recht in het Belgische pantheon een plaats zouden innemen naast de zeshonderd Franchimontezen en Frans Anneessens" (Weisgerber 1962: 229). Hij plaatst opvallend genoeg Jan de Lichte niet in een Vlaams, maar een Belgisch heldenpantheon. Boon speelt inderdaad niet de nationale kaart, maar benadrukt later in zijn romans vooral sociale aspecten in zijn personages.

In de traditie van wisselende narratieven van onze Slowaakse held Jánošík wordt in de jaren vijftig en zestig in de officiële geschiedschrijving vooral zijn bendeactiviteit voorgesteld als een strijd tegen de feodale toestanden, tegen de rijken, de hogere klasse en krijgt de Jánošíkfiguur een aura van sociaal revolutionair. Deze voorstelling werd door folklorist Andrej Melicherčík in twee werken onderbouwd $(1952,1963)$ en deze werken bleven lange tijd toonaangevende werken in het onderzoek naar Juraj Jánošík vanuit folkloristisch perspectief. Hroboň en Krištofík (2014: 152-153) vermelden echter dat de werken van Melicherčík opgebouwd waren volgens de dogmatische stalinistische principes van het socialisme, waarbij Jánošík werd afgeschilderd als een held uit het gewone volk die in opstand kwam tegen de bourgeoisie en de feodale structuren van zijn tijd. Tegelijk zette hij zich af tegen het folklorebeeld dat tot dan van Jánošík geschetst werd, omdat dit folklorebeeld de aandacht afhield van zijn echte strijd als volksrevolutionair strijder. We zouden kunnen verwachten dat aangezien het regime deze socialistische ideologie sterk propageerde, Jánošík in de beeldvorming verder gekarakteriseerd werd als held die sterk opkwam voor het gewone volk. Oorspronkelijk vermelden Hroboň en Krištofík (2014: 155-159) inderdaad deze narratieven ook bij het onstaan van een libretto van een opera aan de hand van Ján Cikker in 1954, maar zij merken op dat er eind de jaren zeventig vooral in literaire beeldvorming er een meer evenwichtig beeld tussen de historische waarheid en de legendarische karaktertrekken optreedt. Ideologische clichés over Jánošík komen vanaf de jaren tachtig steeds minder vaak voor of in minimale mate. Het is vooral het revolutionaire aspect wat voor de socialistische geschiedschrijving belangrijk werd. Het marxistische sociale beeld van de twee casushelden dat vanaf de jaren vijftig dus opkomt, wordt verder getemperd of minder benadrukt in latere adaptaties (Hroboň en Krištofík 2014: 159). Bij Jan de Lichte blijven verdere spin-offs en latere adaptaties vooral gebaseerd op het Jan de Lichteverhaal dat Louis Paul Boon heeft opgetekend, men denke bijvoorbeeld aan de stripreeks uit de jaren tachtig, opgetekend door Nagel, die letterlijk vermeldt, naar de roman van L. P. Boon (Nagel 1985).

\section{Tot slot}

"It protects not against the fact that peasants are poor and oppressed, but against the fact that they sometimes are excessively poor and oppressed. Bandit heroes are not expected to make a world of equality. They can only right wrongs and prove that sometimes oppression can be turned upside down." (Hobsbawm, 1957: 24)

Hobsbawm draagt hier bij aan het beeld dat deze helden eigenlijk niet bedoeld zijn om de mensen sociale rechtvaardigheid te tonen, maar dat zij enkel een teken aan de wand zijn dat het gewone volk de kracht in zich heeft om zich te verzetten. Deze krachtige 
boodschap kwam in de jaren vijftig en zestig zowel in de literatuur als in de wetenschappelijke onderzoeken (met marxistische onderbouw) naar rural outlaws in de kijker en raakte later ondergesneeuwd in andere narratieven naargelang de beeldvorming en de adaptatievormen veranderden, zoals in de kunst, opera, stripverhalen, films, televisieseries. Beide helden in onze casus kennen, als we hun beeldvorming vergelijken, vooral in de jaren vijftig en zestig een focus op hun sociale, revolutionaire aspect.

\section{BIBLIOGRAFIE}

BOEVA, LUC (2009). Rien de plus international. Naar een comparatieve en transnationale historiografie van nationale bewegingen. Antwerpen: ADVN.

BOSSAERT, BENJAMIN (2016). "Primitieve rebellen als helden: voor wie nog een Robin Hood? Literaire en historische representaties van twee nationale rebellen: Jan de Lichte (Vlaanderen) versus Juraj Jánošík (Slowakije)." In: Wilken Engelbrecht \& Bas Hamers. Over de grens bekeken. Transmissie van de cultuur van de Lage Landen. Olomouc: Univerzita Palackého v Olomouci, p. 179-197.

GOSZCZYŃSKA, JOANNA (2003). Mýtus o Jánošíkovi vo folklóre a slovenskej literatúre 19. storočia. vertaald vanuit het Pools: Bogumila Suwara, Bratislava: Juga.

HOBSBAWM, ERIC (1959). Primitive Rebels. Manchester: The University Press.

HOF, WILLEKE VAN 'T (1979). "De visie van L. P. Boon op de geschiedenis van de bende van Jan de Lichte." Ons Erfdeel 22, p. 325-338.

HROBOŇ, ANTON \& KRIŠTOFÍK, JURAJ (2014). “Medzi dobrým umyslom a zneužitím: Jánošíkovská tradicia na Slovensku v rokoch 1938-1989.” In: Miroslav Nemec \& Peter Vítek (ed.), Zbojníctvo na Slovensku. Kraków: Spolok Slovákov v Pol’sku, p. 147-159.

HUMBEECK, KRIS (2007). "Klijster Licht en Zoon. Nawoord." In: Louis Paul Boon, De bende van Jan de Lichte / De zoon van Jan de Lichte, verzameld werk, deel 8, Amsterdam \& Antwerpen: Uitgeverij De Arbeiderspers.

LEERSSEN, JOEP (1999). Nationaal denken in Europa, een cultuurhistorische schets. Amsterdam: Amsterdam University Press.

LEERSSEN, JOEP \& JOHN NEUBAUER, ET AL. (2010). “The Rural Outlaws in East-central Europe”. Marcel Cornis-Pope \& John Neubauer (ed.). History of the Literary Cultures of East-Central Europe: Junctures and disjunctures in the 19th and 20th centuries. IV: Types and stereotypes. Amsterdam \& New York: John Benjamins, p. 407-440.

MAES, PAUL \& STEFAAN TOP (1982). "De Bende van Jan de Lichte. Een vergelijking tussen historische en volksliteraire bronnen." Volkskunde 83, nr. 1, p. 9-27.

MELICHERČÍK, ANDREJ (1952). Jánošíkovská tradícia na Slovensku. Bratislava: n.n.

MELICHERČÍK, ANDREJ (1963). Juraj Jánošík. Hrdina protifeudálneho odboja slovenského ludu. Martin: Osveta.

NAGEL \& PAUL DE WISPELAERE (1985). De bende van Jan de Lichte, door Nagel naar Louis Paul Boon, [i.s.m Jan Smet, Dirk Willemse, Paul De Wispelaere] 5 volumes. '1. Klijsterlicht', Arboris, Aerdenhout i.s.m. Het Spectrum, Antwerpen.

NEMEC, MIROSLAV \& PETER VÍTEK (ed.) (2014). Zbojníctvo na Slovensku. Kraków: Spolok Slovákov v Polsku.

PARLEVLIET, SANNE (2009). Meesterwerken met ezelsoren: Bewerkingen van literaire klassiekers voor kinderen. 1850-1950. Hilversum: Verloren.

RAČKO, PETER (2014). “Zbojníctvo v slovenskej umeleckej literatúre 18.-19. storočia.” In: Miroslav Nemec \& Peter Vítek (ed.) (2014). Zbojníctvo na Slovensku. Kraków: Spolok Slovákov v Polsku, p. 113-137.

VÍTEK, PETER (2014). “Jánošík - pramene a literatúra." In: Miroslav Nemec \& Peter Vítek (ed.), Zbojníctvo na Slovensku. Kraków: Spolok Slovákov v Pol'sku, p. 138-146.

WERNER, MICHAEL \& ZIMMERMANN, BÉNÉDICTE (2003). Beyond Comparison: Histoire Croisée and the Challenge of Reflexivity. In: Annales HSS, Jan.-Feb. 58, 1, p. 7-36. 
WEISGERBER JEAN (1976). Aspecten van de Vlaamse roman, 1927-1960. Amsterdam: Athenaeum-Polak \& Van Gennep.

www1 BROLSMA, MARJET, "Cultuurtransfer en het tijdschriftenonderzoek", COnTEXTES [online], 4/2008, geraadpleegd op 15/02/2018. URL: http://journals.openedition.org/contextes/3823; DOI: $10.4000 /$ contextes. 3823

\title{
HISTOIRE CROISÉE - „INTERKULTURNÍ DĚJINY“ JAKO ZÁKLAD ZKOUMÁNÍ PRIMITIVNÍCH REBELŮ - PŘÍPAD JANA DE LICHTEHO LOUISE PAULA BOONA (VLÁMSKO) A JURAJE JÁNOŠÍKA ANDREJE MELICHERČÍKA (SLOVENSKO)
}

V tomto příspěvku se zaměřujeme na výzkum tzv. sociálních banditů, jak jsou známi ze studie Primitive Rebels Erica Hobsbawma (1959). Zaměřujeme se konkrétněji na př́ípad vlámského Jana de Lichteho a slovenského Juraje Jánošíka. $\mathrm{V}$ tomto příspěvku používáme metodu histoire croisée, kterou navrhli francouzsko-němečtí historici Werner a Zimmermann (2006). Tvrdí, že „interkulturní historie“ sleduje interkulturní vliv na sociální, kulturní a politické skupiny, a nabízejí tak alternativu k dominantnímu národnímu pohledu. Př́spěvek představuje obě hrdinské osobnosti jako hrdiny, jak byli vnímáni $\mathrm{v}$ padesátých a šedesátých letech $\mathrm{v}$ jasně marxistické tradici. Všímáme si rozdílného pojetí ve vlámské literární adaptaci, která zůstává převážně regionálním fenoménem.

\author{
Benjamin Bossaert \\ Univerzita Komenského v Bratislave \\ E-mail: benjaminbossaert@gmail.com
}

